\title{
Violencia, lenguaje y regeneración poética en Juan Mayorga: Hamelin y Reikiavik
}

\section{Emilio Peral Vega}

\section{(2) OpenEdition}

1 Journals

\section{Edición electrónica}

URL: https://journals.openedition.org/cher/1658

DOI: $10.4000 /$ cher. 1658

ISSN: 2803-5992

\section{Editor}

Presses universitaires de Strasbourg

\section{Edición impresa}

Fecha de publicación: 1 diciembre 2017

Paginación: 113-120

ISBN: 978-2-86820-962-7

ISSN: $1968-035 X$

\section{Referencia electrónica}

Emilio Peral Vega, «Violencia, lenguaje y regeneración poética en Juan Mayorga: Hamelin y Reikiavik», reCHERches [En línea], 19 | 2017, Publicado el 01 diciembre 2021, consultado el 03 febrero 2022. URL: http://journals.openedition.org/cher/1658 ; DOI: https://doi.org/10.4000/cher.1658

\section{(c) (i) (ㅇ)}

Ce(tte) œuvre est mise à disposition selon les termes de la Licence Creative Commons Attribution Pas d'Utilisation Commerciale - Partage dans les Mêmes Conditions 4.0 International. 


\title{
Violencia, lenguaje y regeneración poética en Juan Mayorga: Hamelin y Reikiavik
}

\author{
Emilio Peral Vega ${ }^{1}$
}

Con varios los estudios que perfilan el papel central que Walter Benjamin - cumple en la dramaturgia de Juan Mayorga, hasta el punto de que en un reciente estudio yo mismo refería la «geografía benjaminiana» que puede trazarse en su teatro (Gorría Ferrín 2012, Pastena 2012, Peral Vega 2015) ${ }^{2}$. El filósofo judío aboga por una superación del lenguaje actual, dominado por una intención meramente comunicativa; el hombre, si tiene intención de seguirlo siendo, ha de buscar un lenguaje no dominado por la intención del sujeto y, en consecuencia, por un fin instrumental, sino uno más esencial que sea la traducción directa de las cosas, que busque la verdad esencial de ellas (Benjamin 2010). Renuncia, pues, a una dimensión monológica del discurso y privilegia la dialógica, pues es en la exposición de las ideas donde la verdad se manifiesta; una verdad, en otras palabras, que no se vincula al discurso lineal de un yo emisor sino a su quiebra en voces plurales. Ninguna expresión verbal encarna de mejor manera la dimensión dialógica que el teatro. Es el teatro el ámbito, precisamente, donde este proceso revelador se realiza a partir de voces diversas, pero también donde el juicio (la revelación) se suspende (se interrumpe) en tanto que su desvelamiento depende de una instancia ajena a aquellos que la figuran -el público- en un proceso de aniquilamiento sucesivo de la subjetividad.

Dos piezas, bastantes distantes en su estreno -Hamelin llegó a los escenarios en 2005, mientras que Reikiavik lo hizo en 2015-, ejemplifican la continua reflexión que Mayorga otorga al lenguaje, no sólo como depositario humanístico y posibilidad última de generar una historia diversamente rediviva, sino también, y en sentido contrario, como mecanismo para la imposición violenta de

1 Profesor titular de Literatura española en la Universidad Complutense de Madrid.

2 En este sentido, las líneas que siguen sobre Hamelin son una reelaboración de las ya publicadas en la edición que de la pieza realicé para la editorial Cátedra (Peral Vega 2015). 
las ideas. Hamelin es, más allá de la dramatización de una investigación policial en torno a un caso de pedofilia, una reflexión en torno a la derrota del lenguaje como medio exclusivo de comunicación y sobre la violencia, física y psicológica, generada a partir de su concepción falsaria. Todos los personajes exhiben una incomunicación palmaria, con la paradójica excepción -tan mayorguiana como barroca- del verdugo (Rivas) y su víctima (Josemari). El primero es el único que advierte la brecha comunicativa y la necesidad de romperla: "Nadie escucha a los hijos» (Mayorga 2015a: 141); y el segundo, abandonado por sus padres a la voluntad del pedófilo, busca un medio de comunicación convulso en el dibujo, un código sustitutivo en el que se cobija la capacidad de representación emocional y humanística que el lenguaje verbal ha perdido -de forma paralela al ajedrez en Reikiavik, como veremos-. En Hamelin los diálogos se suceden para evidenciar el alejamiento progresivo de los personajes; sólo como contrapunto a esta incomunicación se explica la figura del Acotador -eco brechtiano- quien hace palabra -en apariencia redundante- las acciones que a continuación ejecutan los demás. Se trata de apuntalar teatralmente, de fijar en el tiempo poético de la palabra ajena el lenguaje muerto que encarnan los diversos personajes.

En la ecuación lenguaje-violencia que Mayorga pergeña en Hamelin ${ }^{3}$, creo que podemos establecer tres niveles bien diferenciados:

1. Lenguaje violentado. Nos referimos al proceso de desacralización y perversión al que, de manera creciente, son sometidas las palabras. Cuando el caso de pedofilia comienza a remover las vísceras del público, el Acotador detiene la acción con una doble finalidad: ironiza, en primer término, sobre el carácter elusivo y mentiroso que el lenguaje ha adquirido en nuestra sociedad y, como consecuencia, hace tambalear los parámetros éticos del auditorio que, al fin, llega a plantearse qué resulta más depravado, la manipulación lingüística de la que vamos a ser testigos o las evidencias -tan sólo apuntadas y nunca confirmadas- del presunto abuso sobre el menor. Un lenguaje, en efecto, que ha perdido su relación íntima y original con la realidad misma y se ha convertido en un medio de adornarla, evitarla y falsearla:

«Proyecto». Está hablando de un niño de diez años. «Proyecto». La palabra debería retumbar en el teatro. Palabras: «Escuela Hogar», «Dirección General de Protección de la Infancia», «Derechos Humanos». Esta es una obra sobre el lenguaje. Sobre cómo se forma y cómo enferma el lenguaje. Al otro lado de la mesa, Raquel sigue hablando. No dice «familia», dice «unidad familiar». No dice «Josemari», dice "paciente». Raquel sigue hablando y Montero mira por la ventana. En la acera, los niños juegan al fútbol. Montero se fija en uno que no

3 Fue estrenada el 12 de mayo de 2005 en el Teatro de La Abadía de Madrid, bajo la dirección de Andrés Lima al frente del Grupo Animalario. El elenco estaba integrado por Andrés Lima, en el papel de Acotador, Alberto San Juan, como Josemari, Guillermo Toledo, interpretando a Rivas, Blanca Portillo, como Raquel, Javier Gutiérrez, encarnando a Montero, Roberto Álamo, desdoblado en Paco y Gonzalo, y Helena Castañeda, como Feli y Julia, si bien en diversos momentos los actores asumían identidades coyunturales. 
participa en el juego. Montero desearía romper la ventana para ver mejor o para respirar. (2015a: 150)

Un lenguaje violentado que no debe entenderse exclusivamente desde el punto de vista verbal, sino desde coordenadas visuales y acústicas, tan sólo perceptibles en la representación de la pieza llevada a cabo, en una de sus más renombradas apuestas, por el Grupo Animalario. El escenario desnudo que planteaba Andrés Lima no es más que la expresión visual de ese terreno yermo que queda tras la destrucción -teatral también- de la palabra como medio de empatía. Todo ha de construirse desde cero. Y si el teatro era sobre todo palabra, una nueva propuesta habrá de generarse, desde la palabra desnuda, ahora reconfigurada. Escenario vacío con leves sugerencias escenográficas aisladas: una puerta al fondo, un par de sillas que crean los diferentes espacios escénicos, y una jaula con ratas que conecta con El flautista de Hamelin, hipotexto de la pieza; y alguna de índole acústica, tal el caso de la canción Wanna be starting something, de Michael Jackson, acusado en 2005 por abuso de menores.

Estos lenguajes violentados generan un espectador violentado, forzado de manera continua a implicarse y a distanciarse -ficcionalizado, tras la ruptura de la cuarta pared, pasa por ser periodista en una rueda de prensa y, después, carnaza para un grupo de chaperos-, a cuestionarse su papel en la fábula y a determinar hasta qué punto es partícipe de ese acto de supuesta depravación ética y de evidente depravación verbal. Y es que como acto de perversión lingüística cabe calificar las palabras de Paco, padre de la víctima -«mientras Josemari está con Pablo, estás tranquilo porque sabes que no anda metiéndose en líos» (Mayorga 2015a: 123)-, que provocan la huida del escenario de todos los presentes, mientras que el público sigue sentado, callado e inútil, para rebatir la negligencia consentida de un padre irresponsable. En el cuadro 7, un nuevo acto verbal -en esta ocasión la confesión silenciosa de Josemari, que asiente ante la afirmación de Montero, "[Pablo te ha tocado] la colilla» (2015a: 129)- activa un nuevo resorte de culpabilización para el auditorio silente cuando el juez coloca delante de él las diapositivas invisibles que recrean presuntas escenas pedófilas. De forma creciente, y sin pausa, Montero ficcionaliza al público, convertido nuevamente en periodista callado; es así representante de una de las variantes discursivas más pútridas y perversas, pues que no siempre observa el periodismo la conexión veraz entre lo dicho y lo acaecido sino, por el contrario, la recreación morbosa de simples sospechas que alimentan a un receptor igualmente infectado de carencia ética. Y así, de nuevo, en el cuadro 10, cuando el respetable asume la función de juzgado silente, kafkianamente mudo, solazado tras haber encontrado un verdugo en quien proyectar toda la culpa -sobre todo la que ha amasado a lo largo de la representación-. Sin embargo, el supuesto verdugo se levanta y verbaliza un resquicio de duda -«Usted le da un monstruo a la gente y la prensa cuenta cómo era el monstruo de niño» (2015a: 141)-, muy pronto transformada en orden taxativa -«Déjele de hablar» (2015a: 141)- que marca la verdadera función del teatro: incitar a la pregunta más que encontrar una respuesta o un culpable unívocos. 
2. Lenguaje muerto. Hamelin abusa de una escenografía simbólicamente desnuda que se ratifica en un buen número de acciones mimadas en las que la palabra, depauperada por unos y otros, se suspende precisamente para mostrar esa verdad que no nos atrevemos a afrontar. Si palabras certeras deben sustanciarse de una investigación judicial, lo cierto es que la elocuencia más visceral recae en el silencio: el que llena el teatro cuando los chaperos se pasean entre el público para mostrar sus encantos. Y ninguna palabra media en el coqueteo entre el Acotador, Montero y Josemari, ni tampoco en el encuentro en una discoteca de ambiente homosexual entre Gonzalo, primera víctima de Rivas y hermano mayor de Josemari, y el juez Montero. Silencio absoluto también cuando asistimos al arrebato convulso con que Josemari pinta ratas en el suelo del escenario para exorcizar tanto tormento y para, quizás, sentirse más humanamente acompañado que con los suyos.

Este «lenguaje muerto» o, si se prefiere, estas «suspensiones de la palabra» constituyen la forma más extrema de violencia que se puede ejecutar sobre la palabra humanística. Generan, en consecuencia, ya no un espectador en tensión sino un maniatado, pues en su silencio cobarde se siente definitivamente emparentado con aquellos que interpretan las escenas mudas y copartícipe, en fin, de su depravación.

3. Sin embargo, Mayorga es digno sucesor de Buero Vallejo y, por ello, el final deja abierto un posible camino a la redención. Dicho camino está representado por una tercera vía: el lenguaje poético, encarnado en un Montero que recupera la palabra y relata, como lo hiciera su padre en otro tiempo, el cuento de $E l$ flautista de Hamelin a Josemari. Retoma, así, su memoria emocional, aquella que se ha censurado en todo momento para revestirse de una fortaleza que no tiene, y la traspasa, también, a un inocente muy necesitado de afectos.

Una palabra poética por la que Mayorga postula en múltiples ocasiones como antídoto contra los diversos mecanismos de violencia que, a fuerza de ser repetidos, asumimos como normales en nuestra sociedad contemporánea. Quizás el mayor ejercicio de reivindicación esté representado por Angelus Novus ${ }^{4}$, una pieza situada en una ciudad sin nombre cuya población vive aterrorizada por una plaga que causa un número creciente de infectados. Mayorga recrea en esta obra uno de los referentes icónicos de Walter Benjamin, a saber: el cuadro Angelus Novus, pintado por Paul Klee en 1920 y que el propio Benjamin adquirió, cautivado por su simbología polimórfica. Para Benjamin, el ángel de Klee representaba, en su ambigüedad figurativa, la crisis máxima de la civilización occidental y el principio de su regeneración a partir de esta aparición mesiánica.

4 A propuesta del editor Richard Wissbach, Walter Benjamin proyectó, en el verano de 1921, dirigir una nueva revista literaria titulada Angelus Novus. Finalmente los problemas económicos de la editorial impidieron que la idea llegara a buen puerto. Conservamos un texto de Benjamin, "Presentación de la revista Angelus Novus» (1921-1922), que, al parecer, iba a aparecer en el primer número de dicha publicación (Obras, II/ 1, 2010, p. 245-250). 
Aquellos que se encuentran con él quedan infectados, no por contacto físico sino al oír la nueva palabra de esta aparición: la muerte de la palabra como elemento meramente transmisivo y la necesidad, si el hombre pretende seguir siéndolo, de su renacer en una nueva, que lo infecte de conciencia crítica y lo aparte de su naturaleza adocenada.

Un esquema tripartito -lenguaje violentado, lenguaje muerto y lenguaje poético- casi idéntico puede predicarse de Reikiavik, último estreno de Juan Mayorga ${ }^{5}$. A pesar de que el circunstante de la pieza apela al combate ajedrecístico entre Fischer y Spasski, lo cierto es que Reikiavik cabe considerarse una aguda reflexión sobre el lenguaje, sus mecanismos de adulteración y la imperiosa necesidad de su reconfiguración poética. La condición humana se cifra en el intercambio - prioritaria pero no exclusivamente verbal-, con el otro, de forma tal que somos seres dialógicos, de ahí que nuestra identidad individual se convierta en una circunstancia -y no en una esencia- histórica; poco importa en este sentido quiénes eran -quiénes son, pues que el teatro comporta la inmanencia del presente- Fischer o Spasski - «hay infinitas versiones de Spasski, infinitas de Fischer, infinitas de ti» (Mayorga 2015b: 78), ni tampoco quiénes son los parias que, al modo de Esperando a Godot, los interpretan hoy mientras esperan la llegada de alguien que perpetúe su «diálogo»; y sí, por el contrario, quiénes somos en relación con aquel que nos completa -entendiendo esta simbiosis de yo y tú como la verdadera esencia histórica ${ }^{6}-$, con quien hace de nosotros la posibilidad de un pensamiento transmitido y compartido, en cualquiera de las variantes de relación lingüística - por cuanto codificada y recodificable- que se quiera: verbal, sexual o ajedrecística ${ }^{7}$.

Como quería Benjamin, asumir la forma de expresión de los que fueron hace de nosotros otro yo posible, en continua redefinición con otros yoes dialogantes en el hoy y en el ahora: jugar con el pasado, dialogar con él y escribir así un nuevo tiempo: «me compro libros de ajedrez, libros llenos de partidas de jugadores muertos, juego con los jugadores muertos, juego simultáneas con los jugadores

5 El 27 de marzo de 2015 en el Teatro Palacio Valdés de Avilés, en una producción de La Loca de la Casa y Entrecajas Producciones Teatrales, con dirección de Juan Mayorga, y un elenco formado por César Sarachu (Waterloo), Daniel Albadalejo (Bailén) y Elena Rayos (Muchacho). Citamos siempre por Reikiavik, con en ensayo de Fernando Broncano, Madrid, Ediciones La uÑa RoTa, 2015.

6 De forma muy similar se expresaba Cipión en Palabra de perro: «Quizá sólo seamos el delirio de un enfermo. O quizá seamos cada uno delirio del otro, mutuamente creados por el deseo de tener quien nos escuche. Acaso cada uno necesite desdoblarse para hablar consigo mismo. Acaso seamos cada uno el delirio de un perro que teme morir sin haber hablado.»

7 Palabra de perro podría esgrimirse también, en ese diálogo continuo que las piezas de Mayorga ensamblan entre sí, como divagación en torno a los recovecos violentos y poéticos que encierra la lengua, hasta el punto de que en ella reside nuestra dimensión más acabada. Así, en palabras de Berganza: “¿No hablar? ¡Ni hablar! Ahora sé que, si te roban la palabra, te lo roban todo. Mucho me queda por decir. Los sucesos que has oído sobre mis caminos y amos no son nada comparado con...» 
muertos» (2015b: 23), dice Fischer por boca de Waterloo. Ese ayer recodificado e interpretado en diálogo -ajedrecístico y verbal- por Waterloo y Bailén -que son, en el acto creativo de la representación, Fischer y Spasski, pero también la inteligencia soviética y el presidente de los EEUU y los consejeros del jugador ruso y el padre del campeón americano... y tantos otros- supera, porque su intención es artística y pura, al lenguaje violentado y muerto que históricamente se dio y se sigue dando en el presente. Porque, en efecto, Reikiavik coloca sobre el tapete la hipertrofia lingüística aplicada a la educación como mecanismo de distorsión que oculta y empaña el verdadero debate de fondo sobre qué enseñar y cómo hacerlo a nuestros jóvenes: «No tiene tiempo. A segunda hora, examen oral final global. Total. Vital. No puede entretenerse comparando versiones. ¡Se juega el curso!» (2015b: 18).

Pero también muestra los resortes espurios de una de las variantes discursivas -la política- más adulteradas. El ajedrez, como código de comunicación, queda así irremediablemente manchado, pues sobre él se cierne un conjunto de intereses que Nikolái (y Vladímir y Dimitri y Mijaíl y Vasili -encarnado(s), en un continuo vaivén de máscaras, por Waterloo-) verbaliza como forma de presión sobre Spasski. En este sentido, el ejercicio de retórica vacua que el consejero soviético realiza con Spasski como destinatario es modélico, puesto que exhibe, sin tapujos, los mecanismos de adulteración violenta de la verdad ${ }^{8}$; en primer lugar, la ocultación: «Dedicaremos a tu derrota en la tercera partida doce líneas en la parte baja de una página izquierda de Pravda...» (2015b: 66-67); en segundo término, la falsa apelación de pertenencia a un conjunto social de cuya estabilidad se hace responsable al ajedrecista: «Todos estamos juntos en esto, Boris. [...] Desde que perdió en el torneo de Candidatos, al equipo de Taimánov los tratan como apestados» (2015b: 66); en última instancia, el empleo de preguntas retóricas que conforman una amenaza pragmáticamente -Austin dixit- disuasoria y falsaria: "ide verdad quieres vivir en los nueve metros cuadrados que te corresponden?» (2015b: 68), con alusión taimada a la situación económica en que quedaría Spasski si finalmente perdiera el mundial a favor de los americanos.

Las autoridades rusas representan en este sentido la perpetuación de un lenguaje fraudulento utilizado para la imposición y no para el diálogo; una variante monológica del discurso que, obviamente, se relaciona con una concepción filosóficamente moderna -habermaniana, si se prefiere- del pasado. Dicho de otro modo: los grandes personajes y acontecimientos del pasado no son sino argumentos de autoridad a los que se recurre para coaccionar e inducir comportamientos: «Lenin dijo: No hay teoría revolucionaria sin práctica revolucionaria, ni práctica revolucionaria sin teoría revolucionaria. [...] Salvo el poder, todo es ilusión» (2015b: 63). Spasski, al fin mentor de un código poético

8 De nuevo, el juicio de Cipión en Palabra de perro vuelve a jugar como espejo perfecto para Reikiavik: «Di lo que quieras, pero sin hacer sangre. No es bueno que la lengua mate a uno por agradar a otro. Si puedes hablar sin matar, te tendré por discreto.» 
(el ajedrez), contrarresta esta violencia coercitiva invocando a un diálogo humanístico con esos mismos personajes que son apelados en sentido contrario: «También dijo: "soñemos, pero con la condición de creer en nuestros sueños"» (2015b: 64).

El ajedrez, como decimos, se convierte en un código simbólico de regeneración poética entre Waterloo y Bailén, hombres ambos conscientes de su condición coyuntural, pasajera en el devenir histórico de la humanidad y, por tanto, susceptibles de asumir cualesquiera identidad y de ser sustituidos por otros tantos, a sabiendas de que el único requisito insoslayable es que el intercambio comunicativo, planteado desde las coordenadas de la honestidad y la sinceridad, continúe. Desde esta perspectiva cabe entender la sosegada retirada de Bailén, complaciente en dejar su sitio a ese Muchacho que, por obra y gracia de su entrada en el tablero de la palabra compartida, cobra nombre «histórico» de forma espontánea: Leipzig. Dotado ya de una voz humanizada puede plantear, con total solvencia, una nueva variante de la historia:

La noche antes de rendirme, salgo a la terraza con Crimen y castigo. Levanto los ojos al ver a alguien caminando por la orilla. No puedo distinguir su rostro, pero reconozco su modo de andar. Yo también lo veo a él, mirándome desde la terraza. Caminamos por la orilla hasta encontrarnos, caminamos juntos guiados por el ruido de las olas, en el acantilado trazamos con alquitrán un tablero. Rodeados de vientos furiosos, de altísimas olas, jugamos la partida de nuestras vidas. (2015b: 92)

Nótese que el recién llegado aprehende la carga simbólica del ajedrez como código poético, pues esgrime como variante de la historia una partida -una conversación, si se quiere- en medio de la elocuencia natural y al margen, por completo, del ruido de falsedad político. Que su nuevo nombre apele a una ciudad tan íntimamente unida a la música sinfónica como Leipzig -cuna, entre otros, de Richard Wagner- evoca en el espectador nuevos acordes ajenos a la violencia.

\section{Bibliografía}

Benjamin W., 2010 [1916], «Sobre el lenguaje en cuanto tal y sobre el lenguaje del hombre», in: Obras, II/1, Rolf Tiedemann y Hermann Schweppenhäuser (eds.), Jorge Navarro Pérez (trad.), Madrid, Abada, p. 144-166.

Gorría Ferrín A., 2012, «Teatralidad y representación de la Historia: ética, memoria y acción superada en las obras de Juan Mayorga», El Futuro del Pasado. Revista electrónica de historia, 3, p. 481-502.

Mayorga J., 2014, Teatro 1989-2014, Madrid, La uÑa RoTa.

Mayorga J., 2015a, Hamelin. La tortuga de Darwin, Emilio Peral Vega (ed.), Madrid, Cátedra.

Mayorga J., 2015b, Reikiavik, Madrid, La uÑa RoTa. 
Pastena E. (di), 2012, «La forma de la memoria. La Shoah nel teatro di Juan Mayorga», in: Scene di vita. L'impegno civile nel teatro spagnolo contemporáneo, Silvia Monti y Paola Bellomi (eds.), Alessandria, Dell'Orso, p. 23-50.

Peral Vega E., 2015, «Introducción», in: Hamelin. La tortuga de Darwin, Madrid, Cátedra, p. 9-106. 